ARTIGO

\title{
SOCIALIZAÇÃO PROFISSIONAL DOCENTE OU COMO UMA PRÁTICA SE NATURALIZA? UM ESTUDO SOBRE A NATURALIZAÇÃO DO RELIGIOSO NA PRÁTICA DOCENTE
}

\author{
GABRIELA ABUHAB VALENTE ${ }^{1}$ \\ ORCID: https://orcid.org/0000-0003-0737-2432
}

\begin{abstract}
RESUMO: Dois estudos etnográficos realizados entre 2013 e 2019 revelaram a presença naturalizada de recursos de caráter religioso na prática docente de professores do Ensino Fundamental. O objetivo deste ensaio é propor uma reflexão sobre os fatores externos (cultura, contexto histórico e deontologia profissional) e internos (socialização profissional e condições de trabalho) à prática docente que contribuem para o processo de naturalização do uso do religioso como um recurso pedagógico e didático. Para tanto, partimos de uma análise bibliográfica de textos franco-luso-brasileiros em história e em sociologia da educação que abordam a questão da religião no sistema educativo. Ademais, as teorias da socialização profissional e da profissionalização docente foram mobilizadas para a construção da argumentação. Conclui-se que os fatores existentes agem em sinergia e reforçam a possibilidade de utilização de recursos religiosos nas escolas públicas. Este fato é revelador de uma particularidade não apenas da educação brasileira, mas também da configuração social do País, em que a religiosidade marca sua presença.
\end{abstract}

Palavras-chave: Socialização profissional docente, prática docente, religião, recurso religioso.

\section{TEACHERS' PROFESSIONAL SOCIALIZATION, OR HOW DOES A PRACTICE BECOME NATURALIZED? A STUDY ON THE NATURALIZATION OF RELIGIUS ASPECTS IN THE TEACHERS' PRACTICE}

\begin{abstract}
Two ethnographic studies carried out between 2013 and 2019 revealed the naturalized presence of religious aspects in the teaching practice of Elementary school teachers. The aim of this essay is to reflect on the external (culture, historical context, and professional deontology) and internal factors (professional socialization and working conditions) to the teaching practice that contribute to the process of naturalizing the use of religious aspects as pedagogical and didactic resources. To do so, we started from a bibliographic analysis of French-Portuguese-Brazilian texts in history and in sociology of education that approach the issue of religion in the educational system. In addition, contributions from the theories of professional socialization and teaching professionalization were used to construct the argument. We concluded that the existing factors act in synergy and reinforce the possibility of using religious resources in public schools. This fact reveals a peculiarity not only of Brazilian education but of the Brazilian social configuration, in which religiousness is strongly present.
\end{abstract}

\footnotetext{
1 Pós-doutoranda na Université Lumière Lyon 2, Laboratoire Education, Cultures, Politiques (ECP). Lyon, França. <gabriela.abuhab.valente@gmail.com> 
Keywords: Teachers' professional socialization, teaching practice, religion, religious resources.

\title{
SOCIALIZACIÓN PROFESIONAL DE DOCENTES O ¿CÓMO SE NATURALIZA UNA PRÁCTICA? UM ESTUDIO SOBRE LA NATURALIZACIÓN DE LO RELIGIOSO EM LA PRÁCTICA DOCENTE
}

\begin{abstract}
RESÚMEN: Dos estudios etnográficos realizados entre 2013 y 2019 revelaron la presencia naturalizada de recursos religiosos en la práctica docente de los maestros en la escuela secondaria. El objetivo de este artículo es proponer una reflexión sobre los factores externos (cultura, contexto histórico y deontología profesional) e internos (socialización profesional y condiciones de trabajo) a la práctica docente que contribuyen al proceso de naturalización del uso de lo religioso como recurso didáctico y pedagógico. Para eso, partimos de un análisis bibliográfico de textos franco-portugueses-brasileños en historia y en sociología de la educación que abordan el tema de la religión en el sistema educativo. Además, se movilizaron contribuciones de las teorías de la socialización profesional y la profesionalización de la enseñanza para construir el argumento. Se concluye que los factores existentes actúan en sinergia y refuerzan la posibilidad de utilizar recursos religiosos en las escuelas públicas. Este hecho revela una peculiaridad no solo de la educación brasileña, sino también de la configuración social brasileña, en la que la religiosidad está presente.
\end{abstract}

Palabras clave: Socialización profesional de docentes, práctica docente, religión, recursos religiosos.

\section{INTRODUÇÃO}

Esta reflexão apresentada em formato de ensaio foi motivada pelos resultados de duas pesquisas elaboradas entre 2013 e $2019^{2}$. A primeira, realizada no estado de São Paulo a partir de uma etnografia em uma escola municipal, teve como objetivo analisar e identificar a influência da religiosidade dos professores de Ensino Fundamental I na prática docente; no segundo estudo, que seguiu a perspectiva da educação comparada entre as práticas docentes de professores em quatro escolas públicas de São Paulo (Brasil) e Lyon (França), procuramos compreender como os docentes do Ensino Fundamental II agem perante uma situação envolvendo a questão religiosa. As duas pesquisas indicam ${ }^{3}$ que os docentes utilizam suas crenças religiosas durante a atividade docente de forma naturalizada.

Alguns dos exemplos mais flagrantes são a exposição de símbolos religiosos nos estabelecimentos públicos de ensino, os momentos coletivos de oração (normalmente no início do dia e antes das refeições e principalmente com os alunos mais jovens), a busca do "verdadeiro sentido"4 das festas e celebrações religiosas, a escolha de paradidáticos, o argumento da impossibilidade de trabalhar com o texto bíblico fazendo referência ao conteúdo ensinado, e não à liberdade de consciência, dentre outros (VALENTE, 2014, 2015, 2018, 2019).

O que mais surpreende nessas situações é a forma naturalizada da presença do religioso no espaço escolar e, mais especificamente, na prática docente. Entendemos a naturalização como um processo que permite legitimar uma atividade em geral e, no caso deste ensaio, uma prática docente, por meio de uma repetição não reflexiva. A naturalização de uma prática docente pressupõe uma forma de ser, agir e pensar que está validada coletivamente e incorporada na prática desses profissionais. A naturalização é compreendida também como uma economia da ação profissional (CLOT, 2008), ou seja, uma estratégia para que o docente evite os desgastes físico e mental próprios do trabalho, como as rotinas.

\footnotetext{
2 Pesquisas de mestrado e doutorado financiadas pela FAPESP, número dos processos respectivos 2012/23023-3 e 2015/22243-8.

${ }^{3}$ As duas pesquisas foram realizadas, assegurando-se o cumprimento de princípios éticos internacionalmente aceites para a realização de investigação em ciências sociais e humanas.

${ }^{4}$ Uma professora de Ensino Fundamental I utiliza a expressão de "verdadeiro sentido" para fazer referência ao sentido religioso e não comercial das festas religiosas, como a Páscoa e o Natal. 
Fazendo uma comparação com a realidade francesa, com a qual trabalhamos durante a segunda pesquisa (VALENTE, 2019), verificamos que, na França, os professores, por serem funcionários públicos, são submissos a uma injunção de neutralidade, ou seja, eles têm o dever de discrição quanto às suas opiniões e crenças pessoais. A comparação com esta outra realidade leva-nos aos seguintes questionamentos: a partir de quais processos históricos, sociológicos e culturais a religião ou a religiosidade passou a ser utilizada como recurso nas práticas docentes dos professores brasileiros? Quais compreensões e normas guiam o trabalho docente quando o assunto é a questão religiosa? Enfim, a questão que dá título a este ensaio: como se dá o processo de naturalização de uma prática docente?

Partimos de um caso específico, qual seja, a naturalização de elementos religiosos na prática docente. Nossa hipótese é que o processo de naturalização de práticas docentes depende de dinâmicas internas e externas à profissão docente.

Primeiramente, apresentaremos as dinâmicas externas que podem influenciar a naturalização do uso da religião e da religiosidade nas práticas docentes como uma característica da configuração sociocultural brasileira. Em um segundo momento, analisaremos as dinâmicas próprias da profissão, destacando o processo de socialização profissional docente, o qual inclui a formação inicial e a formação em exercício e as condições de trabalho dos docentes, ligadas ao contexto local e à cultura institucional.

\section{ELEMENTOS EXTERNOS}

Denominamos elementos externos aqueles que não fazem parte das dinâmicas internas da profissão docente, mas que possuem uma influência na compreensão da função docente, estando, portanto, mais ou menos ligados à questão educativa no Brasil. Esses elementos são de especial importância para a naturalização do fenômeno religioso na categoria de recurso profissional dos docentes. O primeiro deles é o fator cultural que, servindo como pano de fundo, sustenta as categorias de pensamento de uma sociedade e está relacionado ao processo histórico de construção desta cultura, bem como às normas e leis que objetivam disputas de poder vividas pelo País. Em seguida, interessamonos pela questão da neutralidade ligada à profissão docente, fazendo uma comparação entre a injunção de neutralidade dos docentes na França e o projeto político do "Escola sem Partido" no Brasil.

\section{Religião e educação - alguns elementos históricos e normativos}

Todos os exemplos que apresentamos no início deste texto revelaram contradições que raramente são vividas como tais e que desvelam a busca de um equilíbrio entre o secular e o religioso, que estão em constante tensão. A busca por equilíbrio é atravessada por dois processos sócio-históricos que ocorrem no Brasil de uma forma não linear; são eles: a laicização, definida aqui como um processo que envolve normas jurídicas e políticas públicas; e a secularização, entendida como um processo em que a cultura religiosa se transforma e perde sua força, cedendo espaço para elementos culturais seculares. Como vimos no item anterior, a religião é uma característica muito presente na vida dos brasileiros, portanto podemos afirmar que o Estado brasileiro é laico, mas a sociedade brasileira é pouco secularizada.

A religião no Brasil é um mecanismo regulador da vida da população; os preceitos religiosos estão presentes no calendário (Natal, Páscoa, São João), na comunicação dos brasileiros (Graças a Deus, Ave Maria, Nossa Senhora, Vai com Deus, Fica com Deus etc.) e nas práticas de lazer (frequência na igreja e nos eventos promovidos pela igreja) - em suma, nas formas de ser, agir, pensar e sentir. Tudo isso indica a valorização das religiões pelos brasileiros e revela a centralidade que a religiosidade possui para a população.

É preciso dizer que não são todas as religiões que possuem a mesma posição ou o mesmo valor. As religiões cristãs são mais privilegiadas do que as religiões orientais ou de matriz afro-brasileira. Essa diferença de status não está apenas ligada à hegemonia das religiões cristãs, com a sua superioridade econômica e seu número de fiéis, mas também ao fato de que são religiões prosélitas. Logo, diferentemente das religiões de matriz africana, de religiões orientais e do judaísmo, as religiões cristãs 
têm o objetivo de aumentar o número de fiéis, isto é, de convencer o maior número de pessoas sobre sua "verdade". Ao longo dos últimos quarenta anos, no Brasil e na América Latina, as religiões cristãs não católicas desenvolveram formas de convencimento e evangelização mais eficazes do que a Igreja Católica. Dados do censo de 2010 mostram que mais de $86 \%$ da população brasileira se declara cristã, sendo que o número de evangélicos cresce a cada ano (IBGE, 2010).

A submissão a um processo de socialização em uma sociedade em que a religiosidade é intrínseca, perene e profunda faz com que se incorporem certas disposições de cultura que são, a um só tempo, religiosas e seculares. Dessa forma, tanto a escola (local em que o docente atua e se forma) quanto a igreja, ambas agências socializadoras, agem em interdependência e em sinergia (SETTON, 2005) ao valorizarem uma cultura hegemônica e cristã, mesmo que no nível das ideias: o discurso que prevalece é sempre aquele do respeito à liberdade religiosa (VALENTE, 2019).

Somado a isso, existe uma facilidade de trânsito dos indivíduos entre fronteiras institucionais, sendo esta uma característica histórica da relação entre Estado e religiões no Brasil, como veremos em seguida. Essas fronteiras pouco delimitadas contribuem para que as práticas religiosas atravessem os limiares e intensifiquem o hibridismo existente entre igrejas e espaços públicos, o que não acontece apenas nas escolas, mas também no âmbito político ${ }^{5}$. Assim, as demarcações formais de espaços sociais não são bem delimitadas, permitindo que os indivíduos ajam de maneira criativa, ou seja, que tragam inconscientemente, de forma naturalizada, elementos de uma instituição para outra, da esfera privada para a esfera pública.

O movimento de secularização não é linear e é acompanhado do processo de laicização que, no Brasil, tem início no período histórico de independência, em que ideias iluministas divulgadas por grupos maçônicos começaram a influenciar as ideias da sociedade brasileira (CUNHA, 2017). Contudo, o projeto constitucional existente estabelecia uma simbiose entre Estado e Igreja Católica, garantindo a liberdade religiosa para as religiões cristãs e a tolerância para com outras religiões, ou seja, a prática de religiões não-cristãs impediria o acesso a direitos políticos. Os membros do clero tinham o poder de censurar normas legais que não estivessem de acordo com "a moral e os dogmas católicos", sendo a religião Católica Apostólica Romana reconhecida como a religião por excelência no Brasil.

Essas ideias transformam-se em força política, sobretudo por meio das obras e manifestações dos membros da loja maçônica, Rui Barbosa e Macedo Soares, e do positivista Tavares Bastos, que visavam a separação do Estado e da Igreja como forma de garantir a liberdade religiosa e o progresso do Brasil. Seus entendimentos tiveram influência do lema europeu "Igreja livre no/em Estado livre" (GIUMBELLI, 2002, p. 241; CUNHA, 2017, p.142) e se estenderam também no âmbito da instrução pública. Além dos calorosos debates e publicações de ideias durante todo esse período histórico, em 1879 há uma dispensa de instrução religiosa para não católicos nas escolas primárias públicas; em 1884 há discussões no congresso sobre o assunto, impulsionadas pela Liga do Ensino Leigo (GIUMBELLI, 2002, p. 244) - fundada por Rui Barbosa, em 1883, a partir do modelo de uma sociedade independente chamada La ligue de l'enseignement, de origem belga, em 1854, e depois apropriado pelos franceses em 1866 (BASTOS, 2007) -; e, por último, em 1890, declara-se que os estabelecimentos de ensino primário e secundário devem ser públicos e laicos no Distrito Federal. De forma geral, Giumbelli (2002, p. 245) analisa que as religiões não católicas possuíam uma espécie de liberdade sem igualdade nesse período pré-republicano.

As forças armadas, com o apoio de lideranças civis de partidos republicanos, aproveitaramse da fraqueza da monarquia para um golpe de estado que estabeleceria a República Federativa do Brasil em 1889. Foi esse contexto histórico e social que levou à criação do decreto de separação entre Igreja e Estado, o qual foi incluído na primeira constituição republicana brasileira em 1891. Escrito com a intenção de impedir o Estado de instituir, subvencionar e dificultar os cultos religiosos, esse decreto, na análise de Cunha (2017, p. 24), revela uma ruptura parcial entre as duas instituições (Estado e Igreja), ou

\footnotetext{
${ }^{5} \mathrm{O}$ nome de Deus e o seu poder simbólico são muitas vezes evocados no discurso político, seja para justificar uma ação política, como no caso do voto a favor do impeachment da ex-presidente Dilma Roussef, ou para angariar votos: o lema da campanha presidencial de Jair Bolsonaro é "Brasil acima de tudo, Deus acima de todos". Sem mencionar os projetos de lei que buscam impor uma moral religiosa nas escolas como o "educação sem partido" e o "ideologia de gênero".

Educação em Revista|Belo Horizonte|v.36|e233381|2020
} 
a busca pelo entendimento entre elas e a colaboração recíproca. Esse ato instituiu a liberdade religiosa para todos os indivíduos, inclusive em espaços públicos.

A partir da Constituição Republicana Brasileira de 1891, institui-se o casamento civil, a secularização dos cemitérios, a proibição ao Estado de estabelecer vínculos religiosos e a exclusão do ensino da religião nos estabelecimentos públicos de todo o País. Assim, com a exclusão da Companhia de Jesus do País, a educação de tradição jesuítica e religiosa tornou-se laica ${ }^{6}$ em seus diferentes graus de ensino, sendo que os estados e municípios teriam a responsabilidade de fiscalização. Desde aquele momento, a questão da existência de uma disciplina de instrução religiosa ou ensino religioso tornou-se parte de um debate público bastante controverso.

Entre 1900 e 1920, a ameaça de revoltas militares fez com que as elites brasileiras buscassem uma solução espelhando-se no fascismo italiano, culminando na proposta de implementação do ensino religioso no Brasil de forma facultativa, como uma maneira de impedir a dissolução social, mas que não foi, todavia, aprovada (CUNHA, 2017, p. 509). A Revolução de 1930 levou Getúlio Vargas ao poder, e ele, movido por interesses políticos, em 30 de abril de 1931, decretou o oferecimento da instrução religiosa nos estabelecimentos públicos de ensino primário, secundário e normal, de forma facultativa aos alunos e devendo contar com no mínimo 20 inscrições por estabelecimento.

Após o golpe de estado de 1937, Getúlio Vargas, como estratégia política, procura aproximar-se da Igreja Católica com o objetivo de que os movimentos religiosos se tornem instrumentos de nacionalização, autoritarismo, centralização e modernização. Nesse sentido, o ensino religioso tornase um ensino moralista de uma religião legitimada oficialmente (TOMAZ e TOMAZ, 2016, p. 141).

$\mathrm{Na}$ constituição seguinte, de 1946, o oferecimento do ensino religioso e a influência das lideranças católicas continuaram presentes. No entanto, a disciplina, contrariando a constituição anterior, não teria caráter confessional. Em 1961, o caráter confessional da disciplina volta a ser prescrito constitucionalmente (TOMAZ e TOMAZ, 2016).

O golpe de 1964 institui uma ditadura militar que durou até 1985 e trouxe algumas mudanças no cenário da educação e na relação entre as religiões e o Estado brasileiro. Os militares limitam o poder da igreja, e isso gera um estremecimento das relações entre Igreja Católica e Estado. As disciplinas Educação Moral e Cívica e Organização Social e Política do Brasil - OSPB - são implementadas no currículo brasileiro no ano de 1969, com o objetivo de controlar e submeter os cidadãos à boa moral (VAIDERGORN, 2008). Contudo, os militares percebem que o ensino religioso pode ser um instrumento para o controle civil; assim, em 1971, os professores da disciplina de ensino religioso passam a ser remunerados com financiamento público (TOMAZ e TOMAZ, 2016). Este vai e volta do ensino religioso revela que o processo de secularização da sociedade brasileira possui avanços e recuos, sendo a educação um território de disputa entre as autoridades políticas e religiosas cristãs.

Ainda nos dias de hoje, o artigo $210, \$ 1^{\circ}$, que ratifica o oferecimento da disciplina de ensino religioso na Constituição Federal de 1988, provoca grandes polêmicas, não apenas políticas, mas também discussões no meio acadêmico. Ainda que a maioria dos pesquisadores acredite que a lei pode criar precedentes para a discriminação religiosa, existem aqueles que são engajados na luta pela retirada da disciplina de ensino religioso do currículo escolar (FISCHMANN, 2008, 2009; CUNHA, 2013), e outros estudiosos (GIUMBELLI, 2002; RODRIGUES, 2013) que defendem que a disciplina Ensino Religioso deve ser mantida desde que aberta à pluralidade e à diversidade religiosa.

Outro documento que aborda a questão é a Lei de Diretrizes e Bases (LDB) da Educação de 1996. Após uma mudança estabelecida pelo Conselho Nacional de Educação em 1997, o artigo 33 da LDB afirma que o ensino religioso é parte integrante da formação do cidadão e estabelece que cada estado brasileiro deve se ocupar de regulamentar a disciplina. Além disso, o artigo veda o proselitismo em vista da diversidade cultural religiosa no Brasil, mas permite que a disciplina seja confessional, não confessional ou interconfessional.

A mais recente evolução do ensino religioso foi sua inclusão na Base Nacional Comum Curricular como uma área do Ensino Fundamental. Esta inserção revela a força de bancadas políticas religiosas e, ao mesmo tempo, confirma a naturalização da presença do religioso no espaço escolar, uma

${ }^{6}$ Não existe nenhum documento jurídico que afirme que a educação e/ou o ensino devam ser laicos. Educação em Revista|Belo Horizonte|v.36|e233381|2020 
vez que o documento não traz informações específicas sobre o perfil dos docentes aptos a ministrar a disciplina, nem sobre sua implementação (horário, facultatividade etc.).

\section{Deontologia docente - qual debate público sobre neutralidade?}

Com relação à formação e à prática docente, documentos como a própria LDB, que possui um título sobre os profissionais da educação e que sofreu mudanças com as leis (12.014/2009; 12.796/2013; 13.415/2017), o Conselho Nacional de Educação, com uma resolução de 2015, e o Plano Nacional de Educação (2014-2024) não normatizam a postura dos docentes com relação à questão religiosa, mas enfatizam em diversos momentos o respeito a todas as diversidades sociais, inclusive religiosas, e os diálogos entre as diferentes visões de mundo. Assim, em nenhum desses documentos se fala sobre laicidade ou sobre qual deve ser a postura do profissional perante sua própria crença ou a de seu aluno.

Trazendo um contraponto com a França, a existência de um princípio de neutralidade inerente à função pública ${ }^{7}$ seria uma forma de salvaguardar o profissional. Esta injunção está ligada à uma lógica administrativa (DEROUET, 1992, p. 237) que supõe emancipação, liberdade de expressão e construção de um pensamento crítico (ROBERT; GARNIER, 2015), diferenciando aquilo que é do âmbito do pensamento crítico e da opinião pessoal, mesmo que essa distinção não seja frugal.

A discussão da neutralidade do docente tem sua origem nos pensamentos do filósofo das luzes Condorcet, como elemento de reflexão decorrente do debate sobre a necessidade de separar educação e instrução (MOLE, 2015). Para ele, o papel da educação pública é instruir e não educar, ou seja, ele defende a neutralidade do docente, pois, assim, o direito de educar inerente aos pais estaria garantido. Além disso, instruir permitiria que as opiniões pessoais e familiares fossem independentes, sendo este o principal argumento para a defesa do caráter laico do ensino público. Dessa forma, o ensino da moral deveria ser dissociado de uma moral religiosa. A instrução no espaço público seria, ainda para este iluminista, uma forma de superar os preconceitos da educação doméstica, uma vez que o aluno iria prontamente reconhecer a diferença entre crença e verdade ao perceber que a crença doméstica não é partilhada por todos.

Segundo Mole (2015, p. 43), a recusa de se transmitirem opiniões seria algo intrínseco de um ensino republicano que tem por finalidade a formação de um cidadão responsável e crítico, para que ele não só obedeça às normas sociais, mas também se engaje na mudança por uma sociedade melhor. Além de ter extrema relevância para o aluno, o pensamento crítico ou a vigilância epistemológica é importante também para que o professor possa refletir sobre sua prática docente, duvidar das próprias ideias, descentrar-se de suas opiniões pessoais. A neutralidade francesa pressupõe o impedimento de que o professor utilize a sua própria crença ideológica ou espiritual como instrumento pedagógico.

A questão da neutralidade no Brasil tomou um lugar central recentemente com as discussões acerca do projeto de lei "Escola sem Partido". O movimento "Escola sem Partido", fundado pelo advogado católico Miguel Nagib, tem sua motivação inicial no combate ao "marxismo" e ao "comunismo". Apenas posteriormente incorpora a pauta de combate à "ideologia de gênero", que é quando se aproxima mais fortemente de lideranças evangélicas conservadoras, com a intenção de reprimir professores julgados pelos alunos ou seus pais como contrários aos valores de suas famílias. O projeto construído majoritariamente por militantes conservadores da bancada religiosa (articulados ao PSC, PMDB e PSDB) tem como objetivo último impedir a doutrinação esquerdista por parte dos docentes, mas sobretudo a discussão da questão de gênero. O projeto argumenta pela neutralidade docente, mas não está em busca de uma neutralidade que favoreça o pensamento crítico, mas sim uma suposta neutralidade para que valores religiosos e conservadores sejam reproduzidos nos espaços escolares. Além disso, o projeto seria também uma ferramenta contrária ao uso de algumas normas que constituem a profissionalização, ou seja, a liberdade de cátedra e a autonomia dos docentes de dizer o que pensam e de promover o pensamento crítico.

\footnotetext{
${ }^{7}$ Os professores de escolas públicas e privadas são funcionários públicos na França. Educação em Revista|Belo Horizonte|v.36|e233381|2020
} 
Identificamos, em nossas pesquisas, a existência de uma dificuldade de compreensão dos professores brasileiros sobre a diferença entre pensamento crítico e opinião pessoal. O pensamento crítico ou vigilância epistemológica da prática docente permite uma mudança de olhar, permite duvidar das próprias opiniões, permite o descentrar-se das opiniões pessoais. A neutralidade seria um princípio para impedir que o professor utilizasse a sua própria crença como forma de favorecer a aprendizagem, aspecto esse que, no caso brasileiro, já está naturalizado (VALENTE, 2015; CAPITANIO, 2014).

\section{ELEMENTOS INTERNOS DA PROFISSIONALIZAÇÃO DOCENTE}

Passamos para a segunda parte deste ensaio voltando à nossa pergunta inicial: como uma prática docente se naturaliza? Poderíamos responder essa questão dizendo que, no caso da utilização de recursos religiosos, existe uma conjuntura histórica, normativa, social e cultural para que es ses recursos sejam disponibilizados e legitimados pelos professores. Contudo, nem todas as práticas docentes são naturalizadas dessa mesma forma, e é preciso considerar as dinâmicas internas da profissão. Daremos destaque a duas delas: a primeira é a socialização profissional docente, incluindo desde o processo de escolha da profissão até seu exercício, ligados ao grupo de pares e expectativas sociais; a segunda são as condições de trabalho, relacionadas com os recursos disponíveis e o "efeito escola".

\section{Socialização profissional docente}

A prática docente não é uma prática individual, mas ela revela uma cultura coletiva profissional (NÓVOA, 2019). Isso significa que apenas os próprios profissionais do campo profissional têm os recursos e as estratégias para avaliar o trabalho de seus pares (TARDIF, 2000; LANTHEAUME e HÉLOU, 2008), o que lhes viabiliza uma certa autonomia, mas também um isolamento.

Trata-se de uma atividade profissional que responde a um mandato (HUGHES, 1958), ou seja, o professor possui uma missão ou uma função que corresponde a determinadas normas impostas socialmente'; estas normas, por sua vez, definem as práticas profissionais, os objetos de trabalho e a conduta adequada dos indivíduos. Para Brillet e Gavoille (2016, p. 55), é na relação entre representação da profissão e comportamento dos docentes que se constrói uma identidade profissional para si e para os outros (DUBAR, 2005 [2000]).

A profissão docente, diferentemente de outras profissões, exige o engajamento pessoal do professor. A fronteira entre o público e o privado, entre o espaço profissional e o espaço doméstico é frágil por conta das próprias características da profissão. Por exemplo, o tempo livre de preparação de material e de formação profissional faz com que os docentes busquem atividades de lazer úteis, ou seja, ligadas à disciplina ensinada (LANTHEAUME e HÉLOU, 2008, p. 77).

Concordando com Ambrosetti e Almeida (2009), acreditamos que o processo de aprendizagem da profissão docente tem início na escolarização básica, a partir da observação atenta do próprio professor. Assim, é desde tenra idade que as crianças, pelo contato que estabelecem com os docentes, começam a conhecer esta prática e a construir uma representação da docência ${ }^{10}$.

Esta escolha é, geralmente, uma decisão pessoal relacionada a uma socialização antecipatória (MALET, 2007, p. 665) ou uma imagem profissional (BRILLET; GAVOILLE, 2016) que lhes ensina um discurso sobre sua função social, uma visão sobre a cultura escolar, sobre os desafios que irão enfrentar e sobre a ética profissional. Esse processo de escolha é entendido por Nóvoa (2017, p. 1121) como a transformação de uma predisposição em uma disposição pessoal.

Esse processo continua durante a formação universitária, embora existam impasses e polêmicas sobre a melhor maneira de formar os docentes (CERICATO, 2017; GAT'TI et al., 2019). Nóvoa vê esse período de formação como uma interposição profissional (2017), em que o futuro profissional entra em contato com a profissão, com o conhecimento e com a socialização num

\footnotetext{
${ }^{8}$ Chamamos "efeito escola" as influências e características específicas de um estabelecimento escolar. A discussão sobre o "efeito escola" é bastante presente na literatura francesa. No original, "effet établissement" (VAN ZANTEN, 2004).

${ }^{9}$ Mesmo que nem sempre explícitas.

${ }^{10}$ Evidentemente, não são todas as crianças que vão escolher esta profissão. Educação em Revista|Belo Horizonte|v.36|e233381|2020
} 
determinado universo. Nesse momento da profissionalização, os candidatos adquirem saberes, conhecimentos e competências específicas; além disso, suas expectativas e ideias pressupostas sobre a prática educativa são confrontadas. Nesse sentido, algumas visões de mundo podem sofrer mudanças, isso porque as agências socializadoras pelas quais passamos possuem pesos distintos em nossa vida. É um processo que carrega uma intenção social de valorizar o trabalho, estabelecendo alguns conhecimentos específicos da ocupação (TARDIF, 2000; WITTORSKI; BRIQUET-DUHAZÉ, 2005).

Grande parte dos efeitos da socialização profissional docente consolida-se no momento da atividade empírica profissional ou indução profissional, como prefere Nóvoa (2019), junto aos pares mais experientes e com os alunos, de forma interpessoal, a partir das situações de trabalho, nas situações de trabalho e pelas situações de trabalho (FRANCQ, 1996, p. 14). É nesse momento que cada professor tem a possibilidade de se confrontar e de criar saberes, ou, nas palavras de Nóvoa, criar sua composição pedagógica (NÓVOA, 2017), criar um senso, uma inteligência ou uma compostura pedagógica.

Assim, a prática docente é entendida enquanto causa e consequência de um processo de socialização profissional, a partir da mobilização de experiências profissionais e do diálogo no espaço de trabalho (BOUCHETAL, 2015). A cultura profissional é, dessa forma, estabelecida pelas redes de relações entre os professores. A socialização entre pares coloca em evidência os valores, as formas de ação legítimas e as crenças compartilhadas entre os profissionais que, por vezes, são implícitas - como, por exemplo, a busca por um suporte moral (VAN ZANTEN, 2004, p. 214) que pressupõe uma relação específica com os pares, fazendo com que não se tenha o mesmo tipo de relacionamento com todos os colegas de trabalho. A solidariedade entre os professores como um todo coletivo, ou em pequenos grupos, faz com que haja uma maior ou menor quantidade de trocas informais, o que, por sua vez, exerce um papel importante para a construção da identidade de cada um dos professores, para a relação com os alunos e para a cultura escolar. Dessa forma, a regulação profissional da docência não se dá apenas em nível normativo, ou seja, em âmbito nacional ou estadual, mas também no contexto de uma única instituição escolar, visto que é neste espaço que o docente encontrará seus pares.

Se a socialização profissional docente faz parte da construção identitária dos profissionais, não é possível falar de um único habitus docente, pois ele se constitui a partir de diferentes referências, trajetórias pessoais únicas, caminhos de formação e de particularidades das configurações sociais. Setton (2011, p. 175) sugere a existência de um conjunto de disposições híbridas de habitus que compõem a prática docente. As múltiplas referências que caracterizam as sociedades modernas e que atuam no processo de hibridização, de incorporação e de hierarquização de disposições de habitus, bem como grande parte do trabalho docente, acabam sendo invisíveis, podendo ser identificadas apenas a partir de uma retrospectiva do indivíduo - sobre sua trajetória de vida ou profissional - e da explicitação de situações, nas quais são descritos os usos de disposições enquanto recursos para a ação.

Partindo do processo da construção social da profissionalidade e da socialização docente, procuramos identificar aproximações entre os elementos que compõem a socialização profissional e a naturalização do uso da religião nas práticas docentes, sem a pretensão de dar conta de todas as dimensões dessa socialização.

$\mathrm{Na}$ socialização profissional docente que tem início na escolarização básica, as crianças que serão futuros docentes já podem observar seus professores utilizando elementos religiosos em suas práticas profissionais. Assim, é possível fazer uma representação da prática docente associada a canções religiosas ou elementos de cunho religioso (símbolos, gestos, vocabulários, ritos).

Em seguida, durante a escolha profissional, existe uma influência de uma socialização religiosa na escolha do magistério no Brasil. É possível encontrar cada vez mais religiosas candidatas ao magistério, que escolhem a profissão por recomendação das denominações religiosas das quais participam. Cuidar, educar e catequizar as crianças é visto como missão de mulheres pelas igrejas, principalmente as denominações proselitistas. Portanto, existe uma associação entre a função social de mulher cristã (potencialmente mãe) e a profissão docente idealizada, cuja responsabilidade se concentra em cuidar e ensinar preceitos morais (CAPITANIO, 2013; KNOBLAUCH, 2017).

Ademais, a regulamentação dos cursos de formação docente passa por polêmicas (GATTI et al., 2019), mas as questões de fundo e de estrutura desses cursos são tão mais profundas que nesta discussão não parece haver espaço para a questão religiosa. São raros os debates sobre a laicidade do 
Estado e mesmo sobre a disciplina de ensino religioso nos cursos de ensino superior. Um estudo de Knoblauch (2014) mostra, também, que alunas de graduação em pedagogia em situação de estágio privilegiam conhecimentos aprendidos em sua socialização religiosa, e não nas aulas do curso de pedagogia - ou seja, dentro da hierarquia socializadora, os saberes, competências, recursos e valores provenientes da socialização religiosa são mais fortes do que os recursos da formação universitária e, portanto, da socialização profissional.

Além disso, a modernidade interfere diretamente na socialização profissional do professor, uma vez que a dessacralização da instituição escolar significa que o trabalho docente passa a receber críticas exteriores (alunos, pais, mídias, avaliações nacionais e internacionais) que, por sua vez, são significativas para a construção identitária do profissional, bem como para o julgamento do que é um bom trabalho. Dessa forma, são legitimados novos modelos de autoridade docente, e é exigida uma plasticidade dos docentes para lidar com imprevistos que, por sua vez, acrescentam experiências profissionais para a construção de uma identidade profissional e da profissionalização docente (LANTHEAUME e HÉLOU, 2008, p. 50 e p. 95). Quando os recursos são escassos, a necessidade de improvisação (PAPI, 2018) é evidente e favorece a utilização daqueles que estão facilmente disponíveis. Papi (2018) mostra em seu estudo que são raros os docentes que buscam por legislações ou documentações normativas sobre a prática docente quando se sentem desamparados. Assim, os recursos religiosos aparecem como "estratégias de sobrevivência" (HUBERMAN, 1995), pois são fáceis de utilizar, sobretudo pelo fato de terem sido incorporados pelos docentes durante suas trajetórias de vida ${ }^{11}$. Por exemplo, no estudo de 2013, todos os 18 professores entrevistados eram cristãos de diferentes denominações religiosas; uma professora, inclusive, fazia parte da escola dominical de sua igreja.

Por fim, ainda em âmbito coletivo, podemos apontar a interação com colegas na busca de um suporte moral como mais um elemento naturalizador do uso da religião na prática docente. Os professores iniciantes recebem conselhos que fazem parte de um consenso forte entre os professores, entre outros: o uso da religião ajuda a acalmar os alunos e previne atitudes de violência e uso de drogas. É com este argumento que docentes defendem grupos de cultos religiosos dentro da escola e práticas religiosas. Quando questionados sobre a laicidade, os docentes afirmam que a prática não fere tal princípio, uma vez que "todas as religiões levam ao mesmo fim, ao mesmo Deus" ${ }^{12}$.

Pudemos verificar que as disposições profissionais e religiosas de cada professor se misturam e contribuem para a construção de identidade do indivíduo professor (VALENTE, 2018). Os conhecimentos e os valores adquiridos em instituições distintas possibilitam que ele aja de forma criativa, por não haver delimitações existentes, formações consistentes ou normas prescritas que abordem a interface educação e religião.

As práticas docentes que fazem uso de elementos religiosos, como a escolha de livros paradidáticos, o ensino de canções religiosas e as rezas em momentos solenes, não são questionadas pelas novas gerações de docentes ou por colegas que, mesmo que não estejam de acordo, não possuem respaldo legal para a quebra de tradições dentro da escola. Dessa forma, a presença dos crucifixos e Bíblias no espaço escolar, as celebrações de cunho religioso e outras práticas religiosas nas escolas públicas continuam a existir e passam a fazer parte de uma tradição ligada à cultura escolar.

A implicação do docente na profissão faz com que ele deseje o que é melhor para seus alunos. Os professores possuem uma prática benevolente, coberta de boas intenções, mas o restrito acesso a formações, a recursos e à não conscientização de suas próprias crenças favorece a naturalização do uso da crença religiosa como recurso didático e pedagógico.

\section{Condições de trabalho}

\footnotetext{
$11 \mathrm{O}$ uso da internet é também bastante comum entre os docentes como ferramenta para a busca de recursos didáticos e pedagógicos.

${ }^{12}$ Fala de uma diretora de uma escola pública estadual que oferece o Ensino Fundamental II. Durante as duas pesquisas realizadas, outras falas com este mesmo teor foram recolhidas de docentes de diferentes disciplinas e das duas etapas de ensino pesquisadas: Ensino Fundamental I e II.
} 
O processo de socialização profissional não é um processo homogeneizante e também não é através dele que pretendemos condenar as práticas docentes e culpar os professores. Esse processo de socialização está ligado às condições de possibilidade, às configurações locais e, sobretudo, à cultura institucional em que ele é desenvolvido.

Dessa maneira, compreendemos que a organização institucional de um espaço e o tempo para as trocas entre os docentes permitem uma maior integração entre os profissionais e, consequentemente, um compartilhamento contínuo de saberes, conhecimentos e competências fundamentais para a (trans)formação identitária de si e da profissão, através de uma normatividade intermediária (LANTHEAUME e SIMONIAN, 2012) através da criação de respostas às injunções normativas a partir do que é possível fazer na prática.

Durante a pesquisa de 2019, pudemos confrontar duas realidades escolares brasileiras que se assemelhavam por serem públicas e por oferecerem o Ensino Fundamental II. Contudo, as condições de trabalho docente eram bastante diferentes. As diferenças entre as duas escolas se explicam pelo fato de uma escola estar associada a uma universidade e a outra, não. Assim, os docentes da primeira escola, Escola Academia, eram funcionários universitários, o que permite afirmar que esta configuração escolar é menos frequente do que a configuração escolar encontrada na Escola Padre Manuel da Nóbrega. Apesar de as duas escolas estarem localizadas em zonas urbanas e fazerem parte da rede estadual de educação, na Escola Academia ${ }^{13}$, os docentes trabalhavam em regime exclusivo e eram melhor remunerados que na escola Padre Manuel da Nóbrega. Além disso, pudemos identificar que na Escola Academia os docentes detinham uma maior reflexão sobre a laicidade e eram menos crentes que os docentes da outra escola ${ }^{14}$. Esses elementos trazem uma série de consequências para o entendimento dos docentes sobre a sua função social e o sobre o exercício profissional.

O fato de ter tempo para se dedicar à própria profissão permite uma reflexividade crítica por parte dos docentes, que motiva seu engajamento em projetos e em dinâmicas pedagógicas que abordam questões mais amplas da sociedade, as quais vão além do currículo prescrito, como a questão religiosa. Assim, quando as condições de trabalho são favoráveis, exalta-se a pluralidade religiosa e questiona-se o lugar da religião na sociedade brasileira, como a existência do projeto Religiões na Escola Academia.

Em contrapartida, na escola Padre Manuel da Nóbrega, onde encontramos maior número de situações em que os professores utilizavam a religiosidade em sua prática docente, e na qual encontramos crucifixos e imagens católicas nos prédios, as condições de trabalho eram mais precárias e o suporte pedagógico, pouco efetivo. Momentos coletivos de oração foram observados antes de reuniões de início e de fim de semestre. Neste caso, há ausência de referências claras que orientem as formas de agir, e os saberes docentes são definidos pelas relações pessoais (AMBROSETTTI; ALMEIDA, 2009), que são envoltas por um caráter religioso.

\section{Respondendo à pergunta: como uma prática docente se naturaliza?}

Não procuramos dar uma resposta definitiva a esta questão, mas apresentar alguns elementos de reflexão que puderam ser identificados na análise de situações que naturalizam o uso de preceitos religiosos na prática docente e que podem dar indícios sobre o processo de naturalização de uma prática docente de forma generalizada.

De forma sintética, poderíamos dizer que existem dinâmicas internas e externas à profissão que permitem o processo de naturalização de uma prática docente. Neste ensaio, destacamos, enquanto dinâmicas externas, a história, as normas legais, os aspectos socioculturais e o debate público no Brasil a respeito da temática da religião; e, enquanto dinâmicas internas à profissão, a socialização profissional (incluindo vivências escolares na educação básica, a imagem profissional, a formação universitária e formação em exercício) e as condições de trabalho. Assim, o processo de naturalização prolonga-se no tempo/na história, possui legitimidade (não é questionada) no grupo profissional, faz parte da construção

\footnotetext{
13 Todos os nomes próprios são fictícios.

${ }^{14} \mathrm{Na}$ escola Padre Manuel da Nóbrega, presenciamos reuniões de professores que se iniciavam com preces religiosas, por exemplo.
} 
identitária do docente e está presente em seu contexto social, depende das condições de trabalho dos docentes e é favorecido por conta de normas e formações que tocam no assunto de forma superficial.

\section{CONSIDERAÇÕES FINAIS}

O fato de o sistema educativo brasileiro não ter normas claras sobre a relação existente na articulação entre educação e religião faz com que se exija dos docentes e dos funcionários da educação uma postura de regulação da própria atividade; isso, por sua vez, faz com que o engajamento pessoal do docente no cenário profissional debilite a fronteira entre o público e o privado, permitindo assim que o privado seja um elemento mobilizado no espaço que é público, como no caso da religiosidade dos professores, um recurso facilmente disponível e que, por vezes, se encontra incorporado nas formas de ser, agir, pensar e sentir dos docentes.

A profissão docente evolui a partir de elementos externos e elementos internos, revelando o peso do contexto local na apropriação e adaptação do prescrito para a prática docente, a partir da normatividade intermediária e da utilização dos recursos que estão disponíveis. A naturalização de uma prática docente seria, então, um recurso profissional para preservar a profissão e a si mesmo como uma estratégia de ação que, assim como as rotinas, busca facilitar o trabalho docente e auxiliar o educador na gestão da complexidade das situações, diminuindo assim o investimento físico e cognitivo dos professores (TARDIF, LESSARD, LAHAYE, 1991).

Para concluir, pensamos que é preciso ir além do discurso da diversidade religiosa que, muitas vezes, mascara uma dominação hegemônica. Seria papel dos cursos de formação de professores proporcionar atividades para que os professores se conscientizassem de valores e crenças pessoais e de suas influências no agir docente. Além disso, esses cursos poderiam fornecer ferramentas de busca de recursos em fontes profissionais, por exemplo, valorizando a atividade docente e os saberes construídos durante a atividade profissional.

\section{REFERÊNCIAS}

AMBROSETTTI, Neusa Banhara; ALMEIDA, Patrícia Cristina Albieri de. Profissionalidade docente: uma análise a partir das relações constituintes entre os professores e a escola. Revista Brasileira de Estudos Pedagógicos, Brasília, v. 90, n. 226, p. 592-608, set./dez. 2009.

BASTOS, Maria Helena Camara. Apresentação: a liga do ensino no Brasil e a revista liga do ensino (1883-1884). História da Educação, ASPHE/FaE/UFPel, Pelotas, n. 21, p. 225-246, jan/abr. 2007. Disponível em: file://C:/Users/XX/Downloads/Dialnet-

ALigaDoEnsinoNoBrasilEARevistaLigaDoEnsino18831884-4891591\%20(1).pdf. Acesso em: 28 abr. 2017.

BOUCHETAL, Thierry. Parcours de professeurs des écoles en cours de carrière - épreuves, ressources: pour quel développement professionnel ? Thèse. (Doctorat en Sciences de l'éducation). Université Lumière Lyon 2, 2015.

BRASIL. Constituição da República Federativa do Brasil. Brasília, 1988.

BRASIL. Lei n. 9.394 de 20 de dezembro de 1996. Estabelece as Leis de Diretrizes e Bases (LDB) da Educação Nacional, Diário Oficial da União, ano CXXXIV, n. 248, 23.12.96.

BRASIL. Lei 9.475 de 22 de julho de 1997 que altera a LDB no que concerne ao seu Artigo 33 (sobre o Ensino Religioso). Conselho Nacional de Educação. 1997. 
BRASIL. Lei 12.014 de 20 de dezembro de 1996, com a finalidade de discriminar as categorias de trabalhadores que se devem considerar profissionais da educação. Diário Oficial da União de 07.08.2009.

BRASIL. Lei 12.796 de 4 de abril de 2013. Altera a Lei nº. 9.394, de 20 de dezembro de 1996, que estabelece as diretrizes e bases da educação nacional, para dispor sobre a formação dos profissionais da educação e dar outras providências. Diário Oficial da União de 05.04.2013.

BRASIL. Lei 13.415 de 16 de fevereiro de 2017. Altera as Leis n ${ }^{\circ}$. 9.394, de 20 de dezembro de 1996, que estabelece as diretrizes e bases da educação nacional, e 11.494, de 20 de junho 2007, que regulamenta o Fundo de Manutenção e Desenvolvimento da Educação Básica e de Valorização dos Profissionais da Educação, a Consolidação das Leis do Trabalho - CLT -, aprovada pelo Decreto-Lei n ${ }^{\circ} .5 .452$, de $1^{\circ}$ de maio de 1943, e o Decreto-Lei $n^{\circ}$. 236, de 28 de fevereiro de 1967; revoga a Lei ${ }^{\circ}$. 11.161, de 5 de agosto de 2005; e institui a Política de Fomento à Implementação de Escolas de Ensino Médio em Tempo Integral. Diário Oficial da União de 17.02.2017.

BRASIL. Lei 13.005 de 2014. Aprova o Plano Nacional de Educação - PNE e dá outras providências. Diário Oficial da União de 26.06.2014.

BRILLET, Franck. GAVOILLE, Franck. L'image métier : exploration d'une notion au cœur du choix professionnel. Management \& Avenir, v.2, n. 84, p. 53-72, 2016. DOI 10.3917/mav.084.0053.

CAPITANIO, Ana Maria. Gênero e crenças religiosas: sentidos da docência entre professoras do ensino fundamental I. Tese (Doutorado em Educação). Faculdade de Educação da Universidade de São Paulo, 2014.

CAPITANIO, Ana Maria. Gênero e crenças religiosas de professoras do Ensino Fundamental I. In: Seminário Internacional Faẓendo Gênero 10 (Anais Eletrônicos), Florianópolis, 2013. ISSN 2179-510X.

CERICATO, Itale Luciane. Sentidos e Significados da Docência, segundo uma Professora Iniciante. Educação e Realidade. Porto Alegre, v. 42, n. 2, pp.729-746, 2017.

CLOT, Yves. Travail et pouvoir d'agir, Paris : PUF, 2008.

CUNHA, Luiz Antonio. O sistema nacional de educação e o Ensino Religioso nas escolas públicas. Educação \& Sociedade. Campinas, v.34, n. 124, Jul-Set. 2013.

CUNHA, Luiz Antonio. A Educação Brasileira na Primeira Onda Laica. Rio de Janeiro. Edição do autor. Disponível em http://www.luizantoniocunha.pro.br/. Acesso em: 10 mar. 2017.

DEROUET, Jean-Louis. École et Justice. De l'égalité des chances aux compromis locaux ? Paris: Éditions Métailié, 1992.

DUBAR, Claude. A socialização: construção das identidades sociais e profissionais. Tradução Andréa Stahel M. da Silva. São Paulo: Martins Fontes, 2005.

FISCHMANN, Roseli. Ensino Religioso em escolas públicas: impactos sobre o Estado Laico. São Paulo: Factash, 2008.

FISCHMANN, Roseli. Constituição brasileira, direitos humanos e educação. Revista Brasileira de Educação, Rio de Janeiro, v. 40, p. 156-167, 2009. 
FRANCQ, Bernard. Introduction. In: FRANCQ, Bernard; MAROY, Christian. Formation et socialization an travail. Paris, Bruxelles: De Boeck \& Larcier S.A. 1996.

GATTI, Bernardete, BARRETO, E., ANDRÉ, M. \& ALMEIDA, P.. Professores do Brasil: novos cenários de formação. Brasília: UNESCO, 2019.

GIUMBELLI, Emerson. O fim da religião: dilemas da liberdade religiosa no Brasil e na França. São Paulo: Attar Editorial, 2002.

HUBERMAN, Michaël. O Ciclo de Vida Profissional dos Professores: diários biográficos. In: NÓVOA, António (Org.). Vidas de Professores. Porto: Porto, 1995, p. 31-61.

HUGHES, Everett C. Men and their work. New York: Free Press, 1958.

IBGE - INSTITUTO BRASILEIRO DE GEOGRAFIA E ESTATÍSTICA. Censo demográfico 2010 Características gerais da população, religião e pessoas com deficiência. Rio de Janeiro, 2013. Disponível em:

ftp://ftp.ibge.gov.br/Censos/Censo_Demografico_2010/Caracteristicas_Gerais_Religiao_Deficien cia/caracteristicas_religiao_deficiencia.pdf. Acesso em: 7 out. 2015.

KNOBLAUCH, Adriane. Relação entre religião, gosto por criança e mudança social: a escolha por Pedagogia. In: MELO, Benedita Portugal e; DIOGO, Ana Matias; FERREIRA, Manuela; LOPES, João Teixeira; GOMES, Elias Evangelista. (Org.). Entre crise e euforia: práticas e políticas educativas no Brasil e em Portugal. 1ed.Porto: Universidade do Porto/Faculdade de Letras, 2014, p. 69-92.

KNOBLAUCH, Adriane. Religião, formação docente e socialização de gênero. Educação e Pesquisa. [online], São Paulo, v.43, n.3, p. 899-914, 2017.

LANTHEAUME, Françoise e HÉLOU, Cristophe. La souffrance des enseignants. Une sociologie pragmatique du travail enseignant. Paris: PUF, 2008.

LANTHEAUME, Françoise e SIMONIAN, Stéphane. La transformation de la professionnalité des enseignants: quel rôle du prescrit ?, Les Sciences de l'éducation - Pour l'Ėre nouvelle, v. 45, p. 17-38, 2012/3. DOI 10.3917/1sdle.453.0017

MALET, Régis. De l'acculturation à la subjectivation. Approche de la formation des enseignants, Ethnologie française, v. 37, p. 663-670. 2007/4, DOI 10.3917/ethn.074.0663.

MOLE, Frédéric. Visées politiques des instituteurs et liberté de conscience des élèves. Autour d'une controverse syndicale des années 1920. In: ROBERT, André e GARNIER, Bruno (Orgs). La pensée critique des enseignants. Éléments d'histoire et de théorisation. Presses universitaires de Rouen et du Havre, 2015.

NÓVOA, António. Firmar a posição como professor, afirmar a profissão docente. Cadernos de Pesquisa [online]. v.47, n.166, p.1106-1133, 2017.

NÓVOA, António. Os Professores e a sua Formação num Tempo de Metamorfose da Escola. Educação e Realidade, Porto Alegre, v.44, n.3. pp. 1-15, 2019.

PAPI, Silmara de Oliveira Gomes. Desenvolvimento Profissional de Docentes Iniciantes na Educação Especial. Educação e Realidade, Porto Alegre, v.43, n.2, p.747-770, 2018. 
ROBERT, André e GARNIER, Bruno. La pensée critique des enseignants. Éléments d’histoire et de théorisation. Presses universitaires de Rouen et du Havre, 2015.

RODRIGUES, Elisa. A formação do Estado secular brasileiro: notas sobre a relação entre religião, laicidade e esfera pública. Horizonte. Belo Horizonte, v.11, n.29, p. 149-174, 2013.

SETTON, Maria da Graça Jacintho. A particularidade do processo de socialização contemporâneo. Tempo social. [online], São Paulo, vol.17, n.2, p.335-350, 2005.

SETTTON, Maria da Graça Jacintho. Prática docente: algumas questões do campo sociológico. InterMeio: revista do Programa de Pós-Graduação em Educação, Campo Grande, v.17, n.33, p. 175-182, jan/jun. 2011.

TARDIF, Maurice. Saberes profissionais dos professores e conhecimentos universitários Elementos para uma epistemologia da prática profissional dos professores e suas consequências em relação à formação para o magistério. Revista Brasileira de Educaşão, Rio de Janeiro, n. 13, Jan/Fev/Mar/Abr 2000.

TARDIF, Maurice; LESSARD, Claude; LAHAYE, Louise. Os professores face ao saber. Esboço de uma problemática do saber docente. Teoria e Educação, Porto Alegre. n. 4, p. 215-233, 1991.

TOMAZ, Loyana Christian de Lima e TOMAZ, Rozaine Aparecida Fontes. Laicidade e religião: um percurso histórico da disciplina Ensino Religioso no Brasil. Trilhas Pedagógicas, v. 6, n. 6, p. 131-150, ago. 2016,

VAIDERGORN, José. Ensino religioso, uma herança do autoritarismo. Caderno CEDES. Campinas, vol. 28 no.76, p.407-411, Sept./Dec. 2008.

VALENTE, Gabriela. Pluralidade religiosa e religião no ambiente escolar. Dans: GAHNEM, E.; NEIRA, M. (Org.). Educaşão e diversidade cultural no Brasil: ensaios e práticas. São Paulo: Junqueira \& Marin.1ed, 2014.

VALENTE, Gabriela. A presença oculta da religiosidade na prática docente. Dissertação (Mestrado em Educação). Faculdade de Educação da Universidade de São Paulo, 2015.

VALENTE, Gabriela. A indissociabilidade de características identitárias dos professores: entre disposições seculares e religiosas. In: SETTON, Maria da Graça. Sociologia da socialização: novos aportes teóricos. São Paulo: FEUSP, 2018, p.186-209.

VALENTE, Gabriela. As práticas docentes e a questão religiosa. Elementos de comparação entre Brasil e França. Tese (Doutorado em Educação). Faculdade de Educação da Universidade de São Paulo. Université Lumière Lyon II, 2019.

VAN ZANTEN, Agnès. L'influence des normmes d'établissement dans la socialisation profissionnelle des enseignants : le cas des professeurs des collèges périphériques français. In. TARDIF, Maurice e LESSARD, Claude. La profession d'enseignant aujourd'hui. Évolutions, perspectives et enjeux internationaux. De Boeck Supérieur « Pédagogies en développement », 2004, p.207-223.

WITTORSKI, Richard. BRIQUET-DUHAZÉ, Sophie (coord.). Comment les enseignants apprennent-ils leur métier? Paris: L'Harmattan, 2005.

Submetido: $17 / 02 / 2020$ 
Aprovado: $25 / 07 / 2020$ 